seals. ${ }^{1}$ Dr. Dybowsky passed a year on the Ussour River, and brought a beautiful collection of birds, fish, and quadruped skeletons. His descriptions are sent to the Berlin Museum. Now he is occupied upon the Baikal with soundings and observations on the Baikal seals. He wishes to write a monograph on this particular species of seals. This is nearly all that was done last year, as far as expeditions are concerned, in this part of the world."

My correspondent refers me to the proceedings of the Siberian Geographical Society for further details. It is much to be regretted that this publication, as well as the excellent Calendar of Eastern Siberia are so little known, out of Asia. I further learn that earthquake shocks have been felt at Irkutsk on the $4^{\text {th }}$ of September last, at 2.55 A.M., and a slight one on the $4^{\text {th }}$ of January. The first one came from the east. A clock which was secured by screu's almost an inch long, was left leaning on one side, and both of the screws drawn completely out of the wall. The Baikal district is the spot in Northern Asia which is most visited by earthquakes.

Since I am on the subject of Siberia, I may mention two facts of considerable interest which I learnt last year. I was told by inhabitants of Jenesseisk that in the regions to the north of that town the compass is of no use during an auroral display. It is not at all unlikely that this should be the case in a country where auroral effects are intense, and the horizontal component of the earth's magnetism is small. The other interesting fact is that Mr. Muller had reached Gauss' Siberian magnetic pole, where he found the needle vertical. This was shortly before I reached Irkutsk. His observations were to be published in the Proceedings of the Siberian Geographical Society. I do not know whether a translation has been published.

Andersonian University, Glasgow, April 4

\section{THE DUBLIN SOCIETIES}

W

have recently referred in several articles to the effors which are being made to introduce a more sati.faciory organisation among the various scientific institutions in Dublin, which have hitherto been independent of each other. It appears now to be proposed not merely to unite museums, but to unite into one body the Royal Irish Academy and the Royal Dublin Society. This project would se $\mathrm{m}$ to have originated at a meeting which a deputation from the latter body had with Major Dunnelly. It is evident that many difficulties would be removed and many advantages result from the amalgamation of these two societies. Of course the arrangements for such an amalgamation must be carried out entirely by the societies, though it would no doubt tend to forward such a scheme if the societies were assured of the approval of Government, and of such aid towards taking the necessary steps as the Government has in its power to give.

We understand further that there is some possibility of an amalgamation of the Royal Agricultural Society of Ireland with the Royal Dublin Society. It is most desirable that such an amalgamation should be effected, and that the agricultural shows should be removed from the present buldings beside Leinster House to the Phœnix Park.

From a letter which has been published in the Irish papers, it appears that these points have been submitted by Major Donnelly to Lord Sandon, who has informed him that the Government are prepared to aid the amalgamation and to give the necessary space in the Phonix Park.

Should the amalgamation be effected, it would probably

I Lake Baikal is remarkable, among other things, for the presence of took a phine animals. The seals are grey, and have a very coarse fur. took. F. take the form of a new Society with a limited number of Fellows, ordinary members, and an Arricultural Section.

It is possible enough that some of the members of the Royal Irish Academy may object to the proposed change, on the score that they would thus lose caste. We cannot adrnit the validity of such an objection. The Academy has no doubt done good work, but it has a large number of members on its roll who are no more entitled to any scientific or literary distinction than the general body of the members of the Royal Dublin Society. If, however, the Academy consent to the proposed change, the Fellowship of the new Society would become a high and much-coveted honour, and the reputation of the whole body would be far higher than that of the separate societies is now. As to the objection that the large body of general members are unfit to select Fellows, we think that the Fellows may very well be entrusted with the selection of Fellows; the first Fellows under the new charter might be, say Fellows of Trinity College, Dublin, Professors and ex-Professors of a College or University, and others with similar positions, who should be empowered to choose their successors. There need be no difficulty, while acting with perfect fairness and openness, in choosing for the inner circle and also for the governing body the best men of the new society, men who would make a point of maintaining its honour and dignity. The Royal Irish Academy would thus become, under a new name, a select body of Fellows chosen for their scientific and literary merit ; in time, indeed, this fellowship might come to be regarded as an honour little inferior to that of F.R.S.

The union of the societies would remove many diffculties as to ownership of property, and would place at their disposal a much larger amount of funds for scientific and literary work than they at present possess. Indeed, it appears to us that from the union on the proposed basis, nothing but good could result, great benefits to the members, and much greater advantages than at present exist for the promotion of science in Ireland. Since government has promised to aid the United Society as far as possible, we think it would be a pity if any petty spirit of local jealousy should raise obstructions to the accomplishment of a scheme which promises so well for the country.

\section{GERMANY AND THE LOAN EXHIBITION}

THE German Committee for the London Loan Exhibition of Scientific Apparatus has addressed a report to the Crown Prince and Crown Princess of Germany on the success of their efforts. It results from this document that 3 I German exhibitors will be represented by 2,492 objects. The 19 classes will be represented as follows:-

i. Arithmetic by

2. Geometry by

3. Measurement by

4. Kinematics by

5. Molecular Physics by

6. Sound by ...

7. Light by $\ldots$.....

8. Heat by

Io. Electricity by

II. Astronomy by

12. Applied Mechanics by

13. Chemistry ${ }^{1}$ by ... ...

14. Meteorology by

15. Geography by ...

16. Geology by

17. Mineralogy by ...

r8. Biology by $\ldots \ldots$. $\ldots 54$

6 exhibitors and I o oujecis.

The space claimed by the exhibitors will be rog square metres floor, 442 square metres repositories (tables, \&c.), 299 square metres wall. Considering that two months had to suffice for bringing together this collection, that manu-

I Exclusive of the collective exhibition of the German Chemical Society, which will represent about 40 exhibitors with 300 objects. 